\title{
Influences of Non-Financial Factors and the Sustainability of Micro Hydro Plants in Malawi
}

\author{
Andrew Munthopa Lipunga ${ }^{1}$ \\ ${ }^{1}$ Faculty of Applied Sciences, University of Malawi-The Polytechnic, Blantyre, Malawi \\ Correspondence: Andrew Munthopa Lipunga, Faculty of Applied Sciences, University of Malawi-The \\ Polytechnic, Private Bag 303, Chichiri, Blantyre 3, Malawi. Tel: 265-999-694-031. E-mail: \\ alipunga@poly.ac.mw
}

Received: December 30, 2016

Accepted: January 21, $2017 \quad$ Online Published: May 31, 2017

doi:10.5539/jsd.v10n3p161

URL: https://doi.org/10.5539/jsd.v10n3p161

\begin{abstract}
The paper evaluates the influence of non-financial factors on the financial sustainability of micro hydro plants (MHPs) in Malawi. It uses case study methodology conducted through interviews triangulated with archival data. The findings suggest the significant role played by non-financial factors on determining the quantity of financing and on long-term financial sustainability for MHPs. This may imply that the difficulties to design suitable sustainable financing models for MHPs may to some extent be attributable to non-financial factors. Therefore when deciding on the appropriate financial measures to address the problem of financial sustainability and in developing financing models of MHPs, consideration should be given to the underlying non-financial factors.
\end{abstract}

Keywords: Bondo Micro Hydro Scheme, financial sustainability, Malawi, Micro Hydro Plants (MHPs)

\section{Introduction}

Micro-hydro plants (MHPs) are one of the forms of renewable energy (RE) technologies proven to be ideal for rural electrification in the Sub-Sahara Africa (SSA), due to the availability of huge resources (Gaul et al., 2010, KPMG, 2014, IEA, 2014). The region is well endowed with huge hydropower resources that are suitable for both big and small scale projects capable to serve both rural and urban populations. However the potential remains untapped in spite of the deep energy crisis being experienced some countries within the region, with rural areas being worst hits. For instance, in rural areas of Malawi where $85 \%$ of the population lives, access to electricity has stagnantly remained below 3\% (African Development Bank Group, 2011, NSO, 2013, Taulo et al., 2015). As a result calls for the exploitation of MHPs in areas with suitable available resources are being made as a way of addressing the energy crisis since they can be implemented relatively quicker and cheaper (IRENA, 2012; KPMG, 2014). However MHPs faces challenges that need first to be addressed to make their widespread adoption possible. One of the major challenges is financing and more especially lack of suitable sustainable financing mechanisms (Klunne, 2009; Taulo et al., 2015; Klunne, 2011; Wohlgemuth, n.d., Pierpont et al., 2011). Available financing mechanisms do not to favour MHPs a thing that suggests the presence of some underlying factors that need to be identified and addressed leading to designing appropriate policy approaches to attract international and domestic financing (Painuly and Fenhann, 2002). The tendency in literature generally has been consider financing challenges simply as one of the major challenges with no clear discussion of their origins. Furthermore the effects of other non-financial challenges on financing are also scarcely discussed. These are significant considerations since financial measures that may be required to be implemented in order to design sustainable financing mechanisms will need to be companied by and coordinated with non-financial measures (IRENA, 2012).

The major challenges hampering widespread adoption of MHPs were summarised into four namely: (1) unclear or non-existence of policies and regulations; (2) missing or very minimal national and regional knowledge and awareness on the potential of small hydro in rural electrification; lack of proper resource data on water availability and flow; and high up-front costs (Klunne, 2012). By their nature, the first three major challenges are non-financial or contextual, whereas the fourth is financial. Although the nature of the three is non-financial, some literature suggests that they have important impact on financing. For instance, IRENA (2012) indicated that contextual challenges can be a source of uncertainties that may result in the market risk for the RE project being perceived by investors as high leading to high cost of capital. Furthermore due to the nature of MHPs, it is 
observed that the cost of electricity production tends to be much higher as compare to both fossil fuels and other RE technologies (Haselip et al., 2011; Ivanova, 2012; Kolk and van den Buuse, 2012; Glemarec, 2012). Besides, the total cost of MHP projects is said to be site specific, varying depending on the remoteness of the site (Anup et al., 2011). Thus non-financial factors appear to have some impacts on the financing that need to be understood and considered in search of sustainable financing models for MHPs.

The purpose of the paper therefore is to empirically evaluate the impacts that non-financial or contextual factors may have on financial sustainability of MHPs in Malawi. This is done by examining the influence of MHP developmental activities (i.e. the physical elements of MHP life cycle) on financing in short and more especially long-term basis. The paper also briefly discusses the shift in financing approach for RE technologies and the key challenges that the traditional sources of finance poses of MHP projects. The rest of the paper is structured as follows. Section two and three discuss the shift in financing approach of RE technologies and challenges that the traditional sources of finance are posing on MHP projects respectively, followed by section four that explains the research methodology. Section five presents the results and ensuing discussion of the case study and finally section six provides the conclusion and recommendations.

\section{Shift in Financing Approach for REs}

Financing of RE technologies is undergoing evolution that policy makers, promoters and operators and other stakeholders need to take cognisance of in their efforts to promote REs. This is in order to ensure that policies and strategies that are adopted are in tandem with the overall financing trend, otherwise they will fail to attract adequate funding. Wohlgemuth (n.d.) noted a shift from the traditional government-and subsidy-centered approach for promotion of RE to the new, market-oriented approach in which consumer-side financing or fee based service is the central factor. More specific to MHPs, Parajuli (2011) observed the evolution in approach in the field of micro-hydro from "technology push" to "market pull". Parajuli (2011) explained that initially micro-hydro installations in developing countries were made to test their technical viability and acceptability, issues that have since been established, and hence the shift to market pull approach which is facilitated by demand based mechanisms or the market forces. The implication of the shift is that commercial viability is becoming one of the important tests that financiers consider before committing their funds hence is turning to be key contributor to financial sustainability. If a project fails the test it is likely to face challenge to assess adequate funding more especially from private financiers. This means policy makers, promoters, and developers of MHPs must be thinking about markets, rather than simply about the RE technologies themselves (Martinot et al., 2002). In the process of encouraging uptake of MHPs, efforts should be made to ascertain the presence of market enabling elements otherwise convincing financiers will become challenging.

One of the major challenges of the consumer-side financing approach for MHP in rural setting in Malawi and most developing countries is that the consumers are typically poor residents (i.e. poor peasants, tenants, landless and other disadvantages group), who are at the bottom of the economic pyramid (Anup et al., 2011). The majority lack sustainable source of income to afford the services this in turn affects the commercial viability of the technology. Economic empowerment measures become necessary in order to enhance the financial capacity of the rural consumers to improve affordability (Parajuli, 2011; Glemarec, 2012). The more effective measures include promoting rural based micro-enterprises and other economic activities (Parajuli, 2011; Glemarec, 2012). In most rural areas therefore the markets for MHPs need creation or stimulation (Haselip et al., 2011) in order to increase the attraction of MHPs for private investment. Moreover economic empowerment measures can go a long way in improving financial capability not only for them to afford the services but more importantly in enabling them mobilise capital amongst themselves to develop a community owned MHP.

In areas where stronger market (i.e. areas where consumers have sufficient financial capacity etc) already exist, may need merely stimulation through consumer awareness and education. It should be noted that failure to develop the market in areas with underdeveloped one will lead it needed continuous assistance in form subsidies or grants to ensure sustainability of the MHP operations. Rational financiers will be discouraged to enter into the sector in that situation. Thus the shift in financing approach calls for corresponding shift in policy and financial mobilisation strategies in that they should factor in conditions of the market. In particular the strategies should take cognisance of the needs of the financiers balanced with the state of the market.

\section{Challenges with the Traditional Sources of Finance}

The traditional sources of finance are posing some challenges to MHP financing worthy serious consideration in search for sustainable financing models. Typically they are three main sources through which capital may be raised for MHP projects namely: equity, debt, and grant (Nasab, 2012). Equity financing entails purchasing of ownership interest in the MHP project whereas debt financing involves giving of a loan to the project (Nasab, 
2012). On the other hand, grants are not repaid; they are normally gratuitous, given as fiscal incentives to increase margin of profitability of the projects since most of RE projects cannot compete with conventional fossil power technologies (Nasab, 2012). The providers these alternative sources of finance may be private financiers, banks, government, donors, end-users (i.e. communities themselves) etc.

The current challenges faced by each form include the following. The providers of equity and debt expect reasonable returns on their investment; hence the MHP project must either be intended to operate at a profit or at least be able to payback the initial investment. This presents a major obstacle to accessing these sources as profitable MHPs are difficult to develop because of the limited size of most local markets (Rodgers, 2009). Besides, the MHP projects often have a payback period exceeding seven years, yet debt financing is often not available for longer than 5-6 years, and equity finance is also rare due to high equity requirement which on average is $40 \%$ (Flavin et al., 2014). Further to that, the economic analysis tend to give insufficient credit for the exceptionally long lifetime and low running costs of micro-hydro because of the widespread short-termism of the modern business world (Paish, 2002). Again, due to the absence of sufficient collateral, banks and investors are not willing to provide loans (at affordable interest rates) in view of long payback periods and problems with cost recovery in general (Kolk and van den Buuse, 2012). Additionally RE technologies being relatively new market players compared to fossil fuel technologies, financial institutions are yet to fully adapt to their unique financing requirements (Flavin et al., 2014), as a result, there is lack of suitable financing instruments.

On the other hand, one of the major challenges in case of grant financing is the fact that these energy access programmes have to compete with other priority programmes for the scarce domestic and international public resources (Glemarec, 2012). Basically, besides energy access, most developing countries have enormous challenges in the areas of education, health, social services, food and human security, basic infrastructure, disaster risk management etc (Glemarec, 2012), as a result, government and donor funding towards RE development is limited (Santiago and Roxas, 2012; UNIDO, 2006; Liu et al., 2013). Other challenge is to do with donor fatigue and differences in priorities, leading to the traditional donor and international agencies advising developing countries to strive for self-financing. For instance, International Monetary Fund (IMF) advised Malawi to stop relying on donor assistance and come up with long-term self-financing measures; the fund noted that donors have their own challenges and priorities that differ to those of Malawi hence it asserted that continuous assistance cannot be guaranteed (Nyasatimes, 2012). The same sentiments were echoed by Britain, another major donor for the country (Kambuwe, 2013, July 12).

The challenges suggest the need for a strategic review of financing landscape and need to take into account financing concerns and motives of financiers when designing of suitable financing mechanisms for MHPs. The traditional forms of financing may be utilised if the MHP projects are perceived as equally competitive like the other investment opportunities. This to some extent indicates the need to improve the market hence commercial viability of the MHP projects in order to enhance their financial sustainability.

\section{Non-Financial Factors and Financial Sustainability}

MHP projects in Malawi are struggling to achieve financial sustainability (McKinnon, 2013), a thing that seems to be a common phenomenon in the Sub-saharan African region. However, there has not been any country specific studies to indentify the underlying factors moreover focusing on non-financial factors. But what is known is that financial sustainability is as a result of interplay of various financial and non-financial factors. Reporting about the means to deal with challenges of financing renewable energy technologies, IRENA (2012A) noted that in order to design sustainable financing mechanisms, financial measures that may be required to be implemented need to be companied by and coordinated with non-financial measures. This was found of essence because basically the unique nature of REs and their related markets, lead to their distinct financing needs (IRENA, 2012A). For instance, in case of MHPs, they are contextual in nature, as such, the total cost of MHP projects - a key financial element, is said to be site specific (Kolk and van den Buuse, 2012; Anup et al., 2011). Accordingly, contextural factors are supposed to be well understood in order to plan and execute the projects. Thus, as noted by IRENA (2012A) market elements as well as the physical aspects do have important influence on financing that need be known and addressed in the search of sustainability of MHPs.

In terms of the physical factors - the nature, IRENA (2012A) observed that each stage of development of REs have distinct financing needs. In harmony, Liebreich (2005) also noted that RE projects are subjected to different types of risk throughout their "life-cycle", each of which requires active management in order to attract financing. These suggest the need to understand what is involved in life cycle stages in order to appreciated and dealing with the resultant effect on financing. This is the case because RE projects are typical example of "new economy enterprises" that demand a financial system that is sufficiently flexible to provide them with different financial 
mechanisms as required by the particularities of their "life cycle" (Thiel, 2001). Thus, in order to understand the totality of financing needs of RE technologies it is imperative to understand each stage and its corresponding financing requirements. Basically the life cyle stages of MHPs are (1) project conceptualisation, (2) feasibility study, (3) designing, (4) regulatory approval, (5) construction, (6) operations and/or extension-of-useful life and (7) termination (Management-hub; Jager and Rathmann, 2008; Pierpont et al., 2011; Razan et al. 2012; Kaunda et al., 2012; ICAST, 2011). Accordingly, this study sought to understanding the influence of these on the financing sustainability of the Bondo Scheme. On the other hand, in terms of the market elements, Kreycik et al. (2010) posited that the market of REs incorporates market acceptance considerations such as demand, supply, commodity prices, regulations, incentives, barriers, investments, and consumer response. Accordingly, Kreycik et al. (2010) identifies regulations, incentives, barriers and consumer response as elements of the market and these are non-financial. Glemarec (2012) also noted that market development for REs involves research and development of policy and regulations, education of consumers and promotion of new income generating activities in the area. Thus in order to understand the influence of market elements the study used policy, regulation, incentives, public awareness and education, community economic empowerment to carry out the test. Easy availability of information about the oppurtunites to developers was also added as an element of the market as that is critical in marketing generally and is sited as one on the major barriers.

\section{Research Methodology}

\subsection{Research Design and Data collection}

The study took a case study research design in evaluating the impact of non-financial factors on financing of MHPs. Basically, case study is used where there is low theory development on the subject matter and the context is very important (Dul and Hak, 2008). These were the factors that led to the choice of design. Generally there is dearth of empirical studies on financial sustainability of MHPs generally and MHPs are contextual in nature as well as the projects costs (Kolk and van den Buuse, 2012; Anup et al., 2011).

Data was collected through interviews and documentary analysis about the scheme. These are the typical data collection methods for case studies (Jankowicz, 2000; Ary et al., 2010). A semi-structured interview protocol was used to ensure that a consistent approach is undertaken in the interviews (Fernández et al., 2011). The protocol consisted of a set of five questions as follows: question one dwelt with identification of the key financing challenges faced by the scheme; second question explored on impact of market elements on financing. Question three asked the informants to summarily point out the specific financial impact of market elements, that is, whether they were: (1) resource consumer; (2) facilitator of resource mobilisation; (3) both 1 and 2; or (4) none. Question four explored the significance of the physical stages in MHP facility development and operations on financing. Finally question five asked the informants to summarily situate the financing impact of the physical stages in question four over MHP life cycle.

In order to ensure effectiveness in data collection, the interview protocol was sent in advance of the interview. The interviews were made with the following key informants namely: 2 managers of the Mulanje Electricity Generation Agency (MEGA), an entity that run the scheme and 1 manager of the Mulanje Renewable Energy Agency (MuREA), an entity that established MEGA and that provides it with technical support. These were the only informants available. As is discussed in section 4.2.2 below, the company managing the scheme is very small having only the three managers that were all interviewed.

In order to broaden the understanding of the contextual challenges in MHP development and operation in Malawi and the rural electrification programme, the two more informants were also interviewed namely: a government official who is a consultant and researcher on MHPs in Malawi. He also carried out the baseline survey on Mulanje Mountain on the same and was part of the team that developed an MHP elsewhere in the country. Furthermore the informant has been following development of the Scheme since its inception. The other informant is a rural electrification practitioner who was responsible for implementing the Malawi Rural Electrification Programme (MAREP).

On the other hand, documentary analysis involved collection of archival data in form of videos, progress reports and other commentaries on progress of the scheme. Much of the data was collected from website of Practical Action (http://practicalaction.org), an organisation which was an implementing partner of the phase one and two of the Bondo Micro-hydro scheme (Mutubuki-Makuyana, 2010).

\subsection{Description of the Case Study}

\subsubsection{Mission and Key Challenge}

The Bondo Micro Hydro Scheme is a classic example of the potential of MHP technology in Malawi; it 
represents a commercial approach to off-grid power in rural Malawi (McKinnon, 2013). Its developmental objective is to provide affordable, sustainable energy to off-grid low income households (McKinnon, 2013; Business Innovation Facility, 2012). The scheme is being developed to run commercially generating income from electricity tariffs that will be reinvested to cover operating costs (Business Innovation Facility, 2012); thus it is based on the modern market-oriented approach. It is the first scheme of this kind in Malawi; hence it is applauded to be a signal for a new era in the country's community energy sector (Malcher, 2013). The key challenge for the scheme is to reach the scale and operational financial sustainability whilst adhering to its founding principles of providing affordable, available, sustainable electricity to the consumers (McKinnon, 2013). The scheme is yet to discover a suitable sustainable financing model, which according to Klunne (2011) should facilitate provision of energy to customers at affordable prices while ensuring its sustainability.

\subsubsection{Establishment and Management Structure}

The scheme was established by a trust called Mulanje Mountain Conservation Trust (MMCT) through its energy agency, the Mulanje Renewable Energy Agency (MuREA) (Mutubuki-Makuyana, 2010; Mhango, 2015). MuREA then established a company called Mulanje Electricity Generation Agency (MEGA) to be responsible for development and operations of the Scheme, as a result, MEGA became the first Independent Power Producer (IPP) in Malawi. It was established to be managed by a General Manager assisted by the Generation Manager and Power Distribution Manager (See Figure 1). At the time of data collection, the position of Generation Manager was vacant as such the Power Distribution Manager was acting also in that position. Besides the existing two managers, there was also a third one attached to the entity from MuREA engaged to promote productive use of energy component of the scheme.

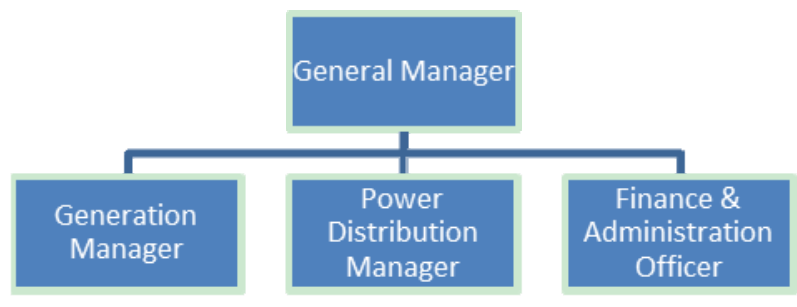

Figure 1. Current organogram of MEGA

\subsubsection{Market and Implementation}

The scheme is built on Lichenya River whose source is the Mulanje Mountain. According to energy capacity estimates, when fully developed and operational, it is expected to generate about 75 kilowatts of power (Mhango, 2015; Kalonga et al., 2013). This is targeted at a potential market of 520,000 people around the area, of which 9,600 households $(42,420$ men, women and children) are expected to be directly connected while the rest of the community members will be benefiting indirectly through better healthcare, education and access to various business opportunities (McKinnon, 2013; Business Innovation Facility, 2012).

The scheme is being implemented in phases. The first and second phases (which are called lower and upper Bondo respectively) were completed, however due to massive floods that hit Malawi during 2014/15 rainy session, the upper Bondo suffered significant damage; rebuilding work started but could not be completed due to the lack of funding. As a result, at the time of data collection only lower Bondo was operational, and was providing electricity directly to 275 households, 8 general dealer shops, 2 schools, a church and a clinic. Besides, power was also connect to a maize mill that is yet to be operational due to technical issues to do with the milling equipments.

\section{Findings and Discussion}

\subsection{Scheme's Key Financing Challenges and Apparent Sources}

The interviews revealed that scheme faces a number of challenges that impact adversely on its financial sustainability. The first challenge is the high capital requirement to have the scheme operating at the expected optimal level. It is projected that the scheme needs to develop additional sites for it to reach a sustainable level. Projecting from the amount of resources consumed to develop lower Bondo to its current level, huge capital is needed. Based on the nature of MHPs, this is not unique to Bondo alone, however ever may be exacerbated by site specific condition (Anup et al., 2011). The second challenge is the difficulty to project the required level of 
funds due to the volatility characterizing the operating environment in Malawi. An example that was cited is the volatility of exchange rate of country's currency that makes planning difficult due the lead time between the time for proposal development and usage of the funds.

The third challenge is the lack of strong support from the government (i.e. various relevant government agencies) that renders development and operation of MHPs in Malawi cumbersome and expensive. There is lack of coordination amongst the government departments, which is in part is due to the fact that the existing energy policies are not clear, their implementation is either inadequate or not in line with the letter and there seem to be no process for monitoring and control. For instances although RE materials are supposed to be imported tax-free, Value Added Tax (VAT) is nevertheless charged with a promise to be refunded later. To the dismay of the developers the claims for refunds are hardly honored or they have to sweat to have them honored. The other example is with regard to regulations, they do not provide for flexibility in relation to size of the operators. They are enforced alike on small and big, new and older players; this creates a heavy overhead burden on small and new players. For instance the licence fees are the same in spite of the size of the operations. The fourth however important challenge is the uncertainties regarding the financial capacity of the end-users. Basically the income of the targeted customers is seasonal, largely depending on farming.

These challenges are critical since they negatively affect the scheme's commercial and financial viability leading it to be entirely dependent on donor. During the eight years of existence both development and operations have largely been financed by the donors. The first and second phases were funded by European Union (EU) and Scottish government through Practical Action and MMCT and the rebuilding of upper Bondo and the third phase are expected to be funded by Global Environmental Facility (GEF) and Scottish government through the partnership of the Malawi Government and United Nations Development Programme (UNDP). The beneficiaries' (community) contribution has been in kind through provision of labour in the construction work, some materials such sand, quarry etc and donation of land (Malcher, 2013; Kalonga et al., 2013).

Accordingly the financing of the scheme has been, to a greater extent, external and philanthropic. It has been running based on philanthropic model as opposed to the commercial model - the modern RE financing approach and the expressed goal of the developers. It should however be noted that the developers are using the philanthropic model in transition to the commercial model. Moreover the current funders are committed to providing funding for the initial developmental phases only (Smith, 2012). Their expectation is that in post-construction phases the scheme will be funded by income generated from electricity tariffs (Smith, 2012). Currently the developers are still in the process of attracting more investment to multiply micro-hydro stations around the mountain; they expect the funds to come through the donors, however, the ultimate plan is to attract commercial investment (Smith, 2012). Thus the MEGA faces a challenge of establishing the scheme as a viable business (Smith, 2012).

Presently, philanthropists remain critical to the success of the scheme; hence measures are needed to be put in place to maximise inflow of aid. Unfortunately, an informant asserted that the current state of the operating environment (the policies, regulations etc) is not competitive enough even to attract more philanthropists to invest in Malawi. Although philanthropists do not expect a monetary return, they have some other motives such as to support environmental purposes, to assist start-up ventures, to encourage energy diversification etc (Foster-Pedley and Hertzog, 2006) which they expect to see coming to fruition within a reasonable period. However due to regulatory hurdles and indecisiveness (as one informant asserted) projects take too long to take sharp and to realise the goals, as a result, Malawi is losing out on many opportunities. It should be borne in mind that philanthropists cannot simply give aid without being convinced of presence favorable conditions; accordingly even success of the philanthropic model depends also on the better operating environment.

On a serious note, informants express concern that government support has largely being in words with limited action on the ground. As already mentioned, some factors cited as evidence of poor support include lack of coordination among government agencies, in that whilst other agencies/departments attempt or apparently seem to have strong desire to promote REs, they are either constrained by the legislations or their effort is impeded by another agency/department. Secondly there is lack of proper structures at local level to coordinate and support RE development and to ensure awareness and promote community empowerment on the same. A specific example mentioned is lack of energy officers at district levels, consequently there is none to promote or translate national energy policies at the local level. Thirdly factor cited was indecision. Informants noted that there is too much bureaucracy in Malawi; for example the enormous documentation in involved, that results in delays in getting approvals to start and implement projects and even in seeking clarification on issues. Furthermore important actions, such as revising the policies and regulations etc takes too long to be undertaken, for example the energy policy was adopted in 2003 and at the time of the research it had not yet been revised. As a result the 
country has instruments that are out of date and not responsive the dynamism of the environment. The fourth factor is that although admittedly the regulations are suboptimal they are however strictly and rigidly enforced on the operators. The regulatory bodies seem to have their hands tied, in that they are unable to exercise discretion in the enforcement of the regulations to the peril of development of the sector with resultant heavy burden on new and small players.

These factors present an unattractive picture to encourage commercial investment in the scheme. As such grant financing remains the only option unless significant transformation is wrought in the operating environment. However grant financing is not sustainable in long term as it equally comes with some strings and is basically intended for initial development stages. Moreover an informant asserted that market for grant finance is very small relative to that for private finance. For long-term financial sustainability of MHPs, attracting private finance should be the ultimate goal.

The analysis of the challenges of the scheme seems to suggests that the factors underlying the financing sustainability challenges are mainly to do with nature of the MHP, policy and regulations and the financial capacity of end-users, hence they are contextual and moreover beyond the control of the scheme, requiring radical transformation of the operating environment. Next section presents some specific influences that physical elements of MHP development have on its financing.

\subsection{Impact of the Physical Factors on Financing of Bondo Scheme}

Developing a viable MHP in harmony with the market-based approach requires development of not only the actual physical asset but also the market. In order to evaluate the impact of the development activities on financial sustainability of the MHPs, informants were asked to state the significance of the physical activities i.e. market and MHP physical facilities of the scheme and the influence they exert on financing.

\subsubsection{Market Development Activities}

An actual RE market incorporates market acceptance considerations such as demand, supply, commodity prices, regulations, incentives, barriers, investments, consumer response etc (Kreycik et al., 2010). Accordingly development of the MHP market involves development of relevant policies and regulations, and education of consumers and community empowerment to enhance affordability of the services (Glemarec, 2012). In order to examine the impact of the market elements on financing, informants were asked to give their assessment of the importance, the challenges and the influence of six market elements namely: national policies, regulations, incentives, public awareness and education, availability of information and community empowerment on financing of the scheme.

\subsubsection{Importance and Challenges of the Market Elements}

\section{National policies}

It was noted Malawi had no standalone policy on RE technologies; however there is an overall energy policy called the National Energy Policy 2003 (Government of Malawi, 2003). It is applauded to be the first ever integrated energy policy designed to guide all energy developments in the country (Phiri, 2014). However it was observed that the policy is out of date and not competitive to attract private investment, hence the scheme cannot really rely on it to obtain private funding. Furthermore the policy deals with all RE technologies as one entity called "Other Renewable Energy Sources" therefore it does not outline specific policy instruments that deal with improving access to the specific RE technologies (Phiri, 2014). As a result, it does not address unique issues and challenges that are specific to each form of RE technologies, in the case of this study MHPs.

\section{Regulations}

MHP development and operations in Malawi are regulated by a number of regulations that include the Rural Electrification Act, Electricity Act, Energy Regulation Act, Environment Management Act, Water Resources Act among others. The regulations were noted to have some significant gaps. The major gap is that they were developed without thinking of the operations of Independent Power Producers (IPPs), as such; they do not provide enough regulatory directions and that cause many delays in the operations of the scheme. On the other hand, it was noted that complying with the regulations requires outlay of resources. Typical costs cited include travelling costs for the interviews with regulators and payments for legal services and licence fees which are overhead burden for small and new operators like the scheme. Furthermore meeting the technical standards set by the regulators demands maintaining the level of quality that also requires outflow of resources.

\section{Public awareness and education}

The informants confirmed the importance of securing support among the beneficiaries - end-users. Basically 
apart from helping the public in making informed decisions on RE, public awareness and education is crucial in providing the knowledge that enhances marketability of the technologies (Phiri, 2014). Although the NEP 2003 requires Government to carry the awareness campaign (Government of Malawi, 2003), which was not the case at Bondo, the developers had to undertake the awareness and education activities themselves. This increased their burden since the activities required expenditure of time and resources. Due to low education level and literacy skills amongst the beneficiaries, as well as limited access to television and radio, there was limited use of written communication; oral communication was found to be the best choice (Bruessow, 2012), accordingly more work had to be undertaken. In spite of that, communication did not represent a high financial cost however it proved to be time-consuming (Bruessow, 2012). It was noted that due to lack of any deliberate awareness program in Malawi, there is poor knowledge about the energy potentials amongst the locals. Informants observed that this was not unique at Bondo only but that it is a general problem in the country; they noted that much of the awareness in Malawi about RE potential is at higher levels of the government.

\section{Incentives}

The informants confirmed the importance of incentives provided by the government on the scheme, this was particularly significant because most of the capital equipments were imported. According the country's policies, $\mathrm{RE}$ equipments are allowed to be imported tax-free as an incentive to accelerate wide spread adoption. The incentives are acknowledged to have the potential for cost savings that can help in reducing the total financial outflow for the scheme. However informants bemoaned that the incentives remain a grey area in that although they may be provided on paper it becomes tough (more of a burden) to access them. For some items, incentives are given in a reactive manner, in that one has to ask in order to get them. There is lack of clear rules as a result the actual impact of incentives on the scheme may be minimal.

\section{Information}

Information availability was confirmed to be critical to the development of the scheme. The challenge faced was that key information about the potential sites was not available. Developers had to collect data and process it themselves. The government has had no known comprehensive program to make necessary information handy in advance. Accordingly time and resources were expended in data collection and processing that otherwise could have been directed towards actual development of the scheme. It was also pointed out that there is general lack of detailed information about the MHP potential sites in Malawi. An informant noted that though there are some attempts made by the government to this effect, they are however fragmented and not holistic, which calls for comprehensive assessment and development of an adequate database.

\section{Community empowerment}

Finally, regarding community empowerment, informants confirmed that the targeted customers have uncertain financial capacity as their income is seasonal dependent on farming. The majority of the targeted users are smallholder farmers who depend on income from tea and other cash crops as pineapples, bananas etc. To ensure constant flow of income through the year, there is a need to boost their financial capacity. This can be done by deliberate economic empowerment programmes targeted at diversifying their income. Due to lack of support from other stakeholders (such as NGOs, microfinance institutions etc), the developers plan to offer some soft loans to the users, a program that will further increases the capital investment requirement and efforts by the developers. It is important to note that enhancement of financial capacity of the users is significant not only because the users' low income capacity but also due to high production costs of electricity that requires charging of a relatively higher tariff. Informants observed that reasonable price for the scheme should be higher than what is charged by the sole national power producer of electricity, the Electricity Supply Corporation of Malawi (ESCOM). The end-users need empowerment to afford the higher price.

As a way of enhancing capacity of the users, the need to promote productive use of energy was highlighted. This basically involves developing small industries in the areas (that create sustainable and effective demand for the MHP facility), than merely supplying electricity for household consumption. The Bondo areas has significant potential for productive use of energy as it is rich in agricultural crops such as bananas, sugarcanes; avocado pears, pineapples, tomatoes and varieties of citrus fruits (Mhango, 2015). Presently the communities lose much of their produce that should been processed right in the area if there had sufficient electricity power (Mhango, 2015). The challenge however is that such initiative can be too much for the developers to undertake alone. Therefore this calls for cooperation with other stakeholders such as the government and other non-governmental organisations. 


\subsubsection{Financial Impact of the Market Elements}

After noting the importance of the market elements, the informants were asked to state the specific financial influence of the market elements; i.e. whether they were "resource consumers", "facilitators of resource mobilisation", "both" or "none of the above". Table 1 below gives the summary of the result:

Table 1. Financial impact of elements of market development

\begin{tabular}{ll}
\hline Elements of market development & Financial impact(s) \\
\hline National policies & Facilitator \\
Regulations & Both a consumer and facilitator \\
Public awareness and education & Both a consumer and facilitator \\
Incentives & Facilitator \\
Availability of information & A consumer \\
Community empowerment & Both a consumer and facilitator \\
\hline
\end{tabular}

The results suggest that market elements have impact on financing of MHP development either or both as resource consumer and facilitator of resource mobilisation. In other words, the results indicate that developing market elements requires outlay of resources and their presence is crucial to attracting resources. On the other hand, absence of the market elements (or if unclear or poorly developed) they adversely affect resource mobilisation, consequently developers face greater challenges to get the desired financial resources in spite of the potential which is not the case when they are present and well developed. As such, where the elements are inadequate, developers are forced to develop them themselves or spend time and effort lobbying for their development as an MHP without a market is not viable; unless it is being developed to run purely based on philanthropic model, in which case it will be subsisting on donations during development and on subsidies over its useful life. However, based on the objectives of the Bondo scheme which commercial, market stimulation is essential. So far the developers have been carrying the burden of developing the market elements alone. This increases the development costs raising further the breakeven point for the scheme. Since no one stakeholder can effectively carry the burden of market development alone (Glemarec, 2012), there is a need for greater stakeholder involvement especially of various government agencies, not only in enforcing regulations but also in carrying the burden of developing appropriate and adequate elements of the market effectively. There is also a need for the growth of the stakeholders' network for the scheme to include skills developers, microfinance institutions and non-governmental organisations need to join forces with the scheme and assist in areas of community empowerment, public awareness and education and in lobbying or helping the government in developing better policies and regulations.

\subsubsection{MHP Physical Facility Development and Operation}

Development of physical facilities of MHPs passes through stages that consume resources. The major interest of the study was to identify the critical stages that significantly define the financing requirements of MHP. This is important because MHPs as "new economy enterprises" demand a financial system that is sufficiently flexible to provide them with different financial mechanisms as required by the particularities of their "life cycle" (Thiel, 2001). Accordingly the informants were asked to describe the impact the seven stages of the MHP cycle to total financing of Bondo Scheme. Furthermore they were also asked to indicate the longevity of their financial impact relative to the life cycle of the scheme - that is whether the particular stage has long or short term impact on financing.

\subsubsection{Impacts of the Stages of MHP Life Cycle}

The study revealed the financial impacts and the opportunities for relieving the cost burden of the developers as follows:

1) Project conceptualization: this is the first stage in MHP cycle whose main aim is to clearly identify the problem (that necessitates the need for the MHP) and present the intervention. It was confirmed that the process required several considerations, consultations and analyses by experts in order to develop the project concept and these consumed time and resources of the developers. Furthermore the process needed services of foreign experts due to poor local capacity. 
2) Feasibility study: added considerable costs to the total cost of developing scheme as it takes much time and involves engagement of experts. In harmony with Kaunda et al. (2012) the study confirmed that feasibility study involved confirming availability of and quantifying the energy generation potential. This stage was noted to be one of the stages that can be targeted to relieve part of the burden of developers. An informant noted that in countries where MHPs have been a success story, governments have been proactive in identifying potential sites and carrying out the feasibility studies. Thus reducing the work and costs borne by developers, a thing that Malawi can adopt.

3) Designing of the plant required expert knowledge in designing as such resources were expended in engaging the experts. The main challenge in Malawi is lack of appropriate human and technical capacity (McKinnon, 2013) and foreign experts are engaged, leading to an increase in the outlay of resources. This further indicates the need to develop local expertise so that some costs can be saved.

4) Regulatory approval process involved engagement of lawyers, attending interviews with the regulators and paying the licence fees. The country's regulations require licence to carry out any sort of rural electrification activity and separate licences are obtained for generation, transmission and distribution (Government of Malawi, 2004A). The major challenge that the scheme encountered was to do with the rigidity of licensing framework (McKinnon, 2013) and the licence fees are said to be expensive for new and small scale operators. An informant noted that the licensing framework makes Malawi less competitive for private investment. An illustrative example was cited of Zimbabwe where small scale operators up a certain level are exempted from paying licence fees as an incentive, a thing that Malawi can adopt as one way of promoting the sector. Due to the rigidity of the framework, the developers had to work diligently with government to agree a new licensing model (McKinnon, 2013); a thing that should not be the case, if the country is to attract investment in the sector. Thus the current licensing framework needs revision to enable IPPs to operate easily (McKinnon, 2013).

5) Building of the plant (physical MHP facility), involved acquisition of various equipments and services and undertaking of civil works that required significant outlay of resources. It is estimated that this stage alone consumed about seventy percentage of the total resource base. Due to lack of equipment manufacturing capacity in the country, most of the equipments were imported; as a result, the scheme faced upfront high infrastructure investment which was also charged in US dollars (McKinnon, 2013). This presents a significant effect on financial sustainability since tariffs are chargeable in Malawi Kwacha (McKinnon, 2013); a relatively weak currency. Furthermore importation of equipments and services caused delays in procurement, which in turn, slowed down the construction and commissioning of the scheme (McKinnon, 2013). Thus localization of manufacturing of the equipments and sourcing of services is critical and important opportunity that can greatly reduce the costs of MHP development.

6) Operations, it was confirmed that operations mainly involves monitoring the system, dealing with customer issues, connecting new customers and carrying out maintenance works. These activities do not consume much resource, however it was noted that maintenance sometimes require replacing of some parts. Due to lack of local manufacturing capacity they need to be imported, resulting in increasing operational costs. Another important issue at this stage is that of pricing. Negotiations had to be made with the government to agree on the tariff since the tariff regime is strictly regulated. Tariffs are set, administered and revised in accordance with the Electricity Act and with the approval from Malawi Energy Regulatory Agency (MERA) (Government of Malawi, 2004B). Although Act allows tariffs to be set at the levels that are sufficient to allow the licensee an opportunity to recover costs of service, including a reasonable return on capital and encourage efficiency, in reality this had been a challenge. The government has previously been more oriented towards achieving social objectives; as a result, it was reluctant to permit an appropriate tariff according to the cost of production. However this orientation has changed shifting towards balancing the social and profit objectives, evidenced by MEGA being issued with a distribution licence allowing it to charge a tariff higher than that of ESCOM. This represents a tremendous shift in policy on the part of the government, which is also in line with the market based approach.

7) Finally, termination, although literature suggests that the plants gets decommissioned after its usefulness, informants could not be drawn to indicate the impact and challenges that that process would have on financing of the scheme. This was due to the fact that the scheme is still in development stage and there is lack of experience in that regard.

The analysis indicates the importance of each stage in the MHP life cycle and the impact on financing except for the termination stage because the scheme is still in infancy. Furthermore study highlighted areas that require improvements and are opportunities for cost reduction. There is need for proactivity more especially on the part of the government. Government action is needed both at macro- and micro-level to develop appropriate and 
relevant policies and regulations and provide assistance to developers to lessen cost burden respectively. There is also a great need for localization of the process of designing of MHP facilities, manufacturing of equipments and spare parts used in building and maintenance of MHP infrastructure. The country needs to develop appropriate local expertise with regard to RE development and operations.

\subsubsection{Situating the Financial Impact of the Physical Stages}

Knowing the longevity of the financial impacts of the stages is important because financial sustainability has long-term orientation in its effect. In order to ensure financial sustainability, the stages with significant long-term financial impacts (in term of resource consumption and resource mobilization) are supposed to be identified and properly managed. The financial impact of the stages may be immediate (short-term impact) or can extend over the life of the plant (long-term impact). Accordingly the informants were asked to identify the stages according to the longevity of their financial impact. Three options were provided to describe the impact namely: (1) only during occurrence of stage activities; (2) over operational lifetime of the plant; and (3) not at all. Option one denoted immediate or short-term impact which suggests that the stage may require relatively less attention, while the second option denoted long-term impact hence critical to financial sustainability. Table 2 presents the results.

Table 2. Financial impact of stages of MHP development over time

\begin{tabular}{|c|c|}
\hline Stages & Financial impacts \\
\hline 1. Project conceptualisation & Immediate impact \\
\hline 2. Feasibility study & Long-term impact \\
\hline 3. Designing of the plant to be built & Immediate impact \\
\hline 4. Regulatory approval & Immediate impact \\
\hline 5. Building of the plant & Long-term impact \\
\hline 6. Operation of the plant & Long-term impact \\
\hline 7. Decommissioning of the plant & Not Applicable \\
\hline
\end{tabular}

As is exhibited on Table 2, project conceptualization, designing of the plant and regulatory approval were said to have immediate financial impacts, whereas feasibility study, building and running of the facility as having long-term financial impact. It is worth noting that, the stages with long-term impacts happens also to be those that consume considerably much of the resources and have significant impact on the other stages. Besides, any material error committed in these stages can be costly to rectify and if not rectified, may have an adverse effect on long-term productivity of the facility. As such, they are critical stages and also good targets for cost containment and management as they also present good opportunities as indicated by the informants.

\section{Conclusion and Recommendations}

The challenges faced by provide sights of the key challenges impeding exploitation of MHPs in the country. The scheme is an attempt to commercialize the technology in a typical rural setting, hence presents an interesting case in tandem with the modern trends in financing of RE technologies. The paper has highlighted some important contextual challenges that have adverse impact on long-term financial sustainability of the scheme. The contextual challenges are presenting significant barriers to private investment as they excarate the project costs and increases uncertainties about financial viability. This leads the schemes survival to be at the mercy of philanthropists. This suggests the critical need to deal with physical or contextual challenges in order to deal with the challenges of the financing of MHPs. Some of the pertinent actions to be effected to improve the situation based on informants recommendations include:

1) Upgrading of the energy policy and regulatory instruments in order to make them clear and responsive to current and future developments in the RE sector and to the dynamism of the operating environment. Possibly the country need to develop a standalone RE policy.

2) Recruitment of energy officers at district level to be responsible for championing energy issues and identifying opportunities at local level.

3) Development of local manufacturing and human resource capacity in order to localize sourcing of equipments and services. 
4) Undertaking community empowerment programme in order to enhance affordability. This particularly calls for the engagement of more stakeholders joining hands with the scheme.

\section{Acknowledgments}

This work is part of a Master of Philosophy (Renewable Energy) programme under the Malawi Renewable Energy Acceleration Programme (MREAP) funded by the Scottish Government which is coordinated by Strathclyde University and Centre for Water, Sanitation, Health and Appropriate Technology Development (WASHTED) at Malawi Polytechnic.

\section{References}

African Development Bank Group. (2011). Malawi, Interim Country Strategy Paper (ICSP) 2011-2012. Retrieved December $25, \quad 2013$ from http://www.afdb.org/fileadmin/uploads/afdb/Documents/Project-and-Operations/Malawi\%20-\%20ICSP\%20 2011-12.pdf

Anup, G., Ian, B., \& Sang-Eun, O. (2011). Micro-hydropower: A promising decentralized renewable technology and its impact on rural livelihoods. Scientific Research and Essays, 6(6), 1240-1248.

Ary, D., Jacobs, L. C., \& Sorensen, C. K. (2010). Introduction to Research in Education (8th ed.). Wadsworth, Cengage Learning Belmont, CA, USA.

Bruessow, C. (2012). Bondo hydro-power development: communication for community engagement in project implementation. $\quad$ Retrieved http://redlac.funbio.org.br/wp-content/uploads/2014/12/Redlac_6_ING_Caso26.pdf.

Business Innovation Facility. (2012). MEGA Creating a Sustainable Micro-hydro Business Model. Retrieved from

http://api.ning.com/files/pCC3UkZfemaaVo4Ewu3Xe2A1HTMxIP7NJf7IdAc*Qsh7pe2a5ciqfk77dtwLpH4 bTUloR*vqo6jrGd81z7jAvZ45rYqUoICu/MEGAprojectprofile_updated_oct2013.pdf

Dul, J., \& Hak, T. (2008). Case Study Methodology in Business Research. Elsevier Linacre House, Jordan Hill, Oxford OX2 8DP, UK.

Fernández, W., Martin, M. A., Gregor, S., Stern, S. E., \& Vitale, M. (2011). A Multi-Paradigm Approach to Grounded Theory. $\quad$ Retrieved November 18, 2014 from http://press.anu.edu.au/wp-content/uploads/2011/08/ch1214.pdf

Flavin, C., Gonzalez, M., Majano, A. M., Ochs, A., da Rocha, M., \& Tagwerker, P. (2014). Study on the Development of the Renewable Energy Market in Latin America and the Caribbean. Retrieved from https://publications.iadb.org/bitstream/handle/11319/6711/Study-on-the-Development-of-the-Renewable-En ergy-Market-in-Latin-America-and-the-Caribbean.pdf.

Foster-Pedley, J., \& Hertzog, H. (2006). Financing strategies for growth in the renewable energy industry in South Africa. Journal of Energy in Southern Africa, 17(4), 57-64.

Gaul, M., Kölling, F., \& Schröder, M. (2010). Policy and regulatory framework conditions for small hydro power in Sub-Saharan Africa. Retrieved January 20, 2015, from http://kerea.org/wp-content/uploads/2012/12/Policy-and-regulatory-framework-conditions-for-small-hydropower-in-Sub-Saharan-Africa.pdf

Glemarec, Y. (2012). Financing off-grid sustainable energy access for the poor. Energy Policy, 47, 87-93. https://doi.org/10.1016/j.enpol.2012.03.032

Government of Malawi. (2003). National Energy Policy for Malawi 2003. Department of Energy, Lilongwe.

Government of Malawi. (2004a). Rural Electrification Act, 2004. Retrieved June 20, 2014, from http://www.meramalawi.mw/documents/rural_electrification_act_2004.pdf

Government of Malawi. (2004b). Electricity Act, 2004. Retrieved June 20, 2014, from www.meramalawi.mw/index.php/legislation/download/2-legislation/5-the-electricity-act-2004

Haselip, J., Nygaard, I., Hansen, U., \& Ackom, E. (Eds.). (2011). Diffusion of renewable energy technologies: case studies of enabling frameworks in developing countries. Technology Transfer Perspectives Series, UNEP Risø Centre, Denmark.

ICAST. (2011). A Practical Approach to Micro-Hydro Power in Colorado: An Educational Outreach Guidebook. Retrieved 
http://icastusa.org/wp/wp-content/uploads/2012/04/A_Practical_Approach_to_Micro-Hydro_Power_in_Col orado1.pdf

IEA (International Energy Agency). (2014). Africa Energy Outlook: A focus on energy prospects in Sub-Saharan Africa. OECD/IEA, Paris.

International Renewable Energy Agency (IRENA). (2012). Financial Mechanisms and Investment Frameworks for Renewables in Developing Countries. Retrieved July 3, 2015, from $\mathrm{http}: / / \mathrm{www}$.irena.org/menu/index.aspx?mnu=Subcat\&PriMenuID=36\&CatID=141\&SubcatID=282

Ivanova, G. (2012). Are Consumers' Willing to Pay Extra for the Electricity from Renewable Energy Sources? An example of Queensland, Australia. International Journal of Renewable Energy Research, 2(4), 758-766

Jager, D., \& Rathmann, M. (2008). Policy instrument design to reduce financing costs in renewable energy $\begin{array}{llllll}\text { technology } \quad \text { projects. } & \text { Retrieved } & \text { January }\end{array}$ http://www.ecofys.com/files/files/retd_pid0810_main.pdf

Jankowicz, A. D. (2000). Business Research Projects (3rd ed.). Thomson Learning, London.

Kalonga, C., Munyoro-Katsi, M., \& Nyathi, T. (2013). Bondo Micro-Hydro Scheme: Improving the lives of the Bondo Community [Video]. Malawi, Practical Action Southern Africa.

Kambuwe, M. (2013). Britain tells Malawi to stop relying on aid. Nyasa Times, 12 July. Retrieved October 1, 2013, from http://www.nyasatimes.com/2013/07/12/britain-tells-malawi-to-stop-relying-on-aid/

Kaunda, C. S., Kimambo, C. Z., \& Nielsen, T. K. (2012). Potential of Small-Scale Hydropower for Electricity Generation in Sub-Saharan Africa. International Scholarly Research Network, 15.

Klunne, W. J. (2009). Small hydropower for rural electrification in South Africa - using experiences from other African countries. $\quad$ Retrieved from http://researchspace.csir.co.za/dspace/bitstream/10204/3757/1/Jonker\%20Klunne_d2_2009.pdf

Klunne, W. J. (2011). Micro hydropower in rural Africa. Challenge, Spring 2011, pp. 6-9. Retrieved from http://practicalaction.org

Klunne, W. J. (2012). Small and micro-hydro developments in Southern Africa. energize - July 2012, pp. 75-78

Kolk, A., van den Buuse, D. (2012). In search of viable business models for development: sustainable energy in developing countries. Corporate Governance, 12, 551-567. https://doi.org/10.1108/14720701211267865

KPMG. (2014). Sub-Saharan Africa Power Outlook. Retrieved June 20, 2015, from http:/www.kpmg.com/ZA/en/IssuesAndInsights/ArticlesPublications/General-Industries-Publications/Docu ments/2014\%20Sub-Saharan\%20Africa\%20Power\%20Outlook.pdf

Kreycik, C., Vimmerstedt, L., \& Doris, E. (2010). A Framework for State-Level Renewable Energy Market Potential Studies. Retrieved from http://www.nrel.gov/docs/fy10osti/46264.pdf

Liu, H., Masera, D., \& Esser, L. (Eds.). (2013). World Small Hydropower Development Report 2013. United Nations Industrial Development Organization; International Center on Small Hydro Power. Retrieved from www.smallhydroworld.org

Malcher, L. (2013). How community energy reached Malawi via Scotland. Retrieved June 13, 2016, from http://www.ashden.org/blog/how-community-energy-reached-malawi-scotland

Management-hub. [Online] Various Phases in a Project Management Life Cycle. Retrieved November 9, 2015, from http://www.management-hub.com/project-management-lifecycle.html

Martinot, E., Chaurey, A., Lew, D., Moreira, J. R., \& Wamukonya, N. (2002). Renewable energy markets in developing countries. The Annual Review of Energy and the Environment, 27, 309-48. https://doi.org/10.1146/annurev.energy.27.122001.083444

McKinnon, A. (2013). MEGA: A commercial approach to off-grid power in rural Malawi. Retrieved from http://www.animus-csr.com/docs/Deepdive_MEGA_HUB.pdf.

Mhango, G. (2015). Water for Electricity: Water Powered Electricity to Transform Malawian Communities. Retrieved

from http://waterjournalistsafrica.com/2015/09/09/waterforelectricitywaterpoweredelectricitytotransformmalawia ncommunities/4/

Mutubuki-Makuyana, C. S. (2010). Financial and ownership models for micro-hydro schemes in southern Africa. 
Retrieved from http://www.hedon.info/tiki-download_item_attachment.php?attId=222

Nasab, A. P. Z. (2012). Financial Analysis of Small-Hydro Power Project in Malaysia from the Investor Perspective. 2012 International Conference on Environment, Energy and Biotechnology IPCBEE vol.33, IACSIT Press, Singapore.

NSO. (2013). 2008 Population and Housing Census Results: Main Report. Zomba: National Statistical Office Malawi.

Nyasatimes. (2012). IMF advises Malawi to stop relying on donors. Nyasatimes, 20 November. Retrieved October 1, 2013, from http://www.nyasatimes.com/imf-advises-malawi-to-stop-relying-on-donors/

Painuly, J. P., \& Fenhann. (2002). Implementation of renewable energy technologies - opportunities and barriers. UNEP Collaborating Centre on Energy and Environment, Riso National Laboratory, Denmark.

Paish, O. (2002). Micro-hydropower: status and prospects. Proc Instn Mech Engrs, 216, 31-40, Part A: J Power and Energy. https://doi.org/10.1243/095765002760024827

Parajuli, R. (2011). Micro and Mini Hydro technologies vulnerability and adaptation to climate change.

Phiri FOM. (2014). Energy Poverty of Rural Households in Malawi: Potential for renewable energy options and more efficient use of biomass to reduce vulnerability. Master Thesis, Department of International Environment and Development Studies, Norwegian University of Life Sciences.

Pierpont, B., Varadarajan, U., Nelson, D., \& Schopp, A. (2011). Renewable Energy Financing and Climate Policy Effectiveness, CPI Analysis Framework (Working Paper). Retrieved from http://climatepolicyinitiative.org/wp-content/uploads/2011/12/Renewable-Energy-Financing-and-Climate-P olicy-Effectiveness-Working-Paper.pdf

Razan, J. I., Islam, R. S., Hasan, R., Hasan, S, \& Islam, F. (2012). A Comprehensive Study of Micro-Hydropower Plant and Its Potential in Bangladesh. International Scholarly Research Network ISRN Renewable Energy, 10 pages.

Rodgers, A. (2009). Sustainable Management of Micro Hydropower Systems for Rural Electrification: The Case of Mt. Kenya Water Catchment Area. MSc thesis, University of Nairobi, Kenya.

Santiago, A., \& Roxas, F. (2012). Identifying, developing, and moving sustainable communities through renewable energy. World Journal of Science, Technology and Sustainable Development, 9(4), 273-281.

Smith, K. (2012). A MEGA Challenge. Retrieved from http://www.inclusivebusinesshub.org/group/malawi/forum/topics/amegachallenge?xg_source=msg_mes_ne twork 16/09/2015

Taulo, J. L., Gondwe, K. J., \& Sebitosi, A. B. (2015). Energy supply in Malawi: Options and issues. Journal of Energy in Southern Africa, 26(2), 19-32. https://doi.org/10.17159/2413-3051/2015/v26i2a2192

Thiel, M. (2001). Finance and economic growth - a review of theory and the available evidence. Retrieved from http://ec.europa.eu/economy_finance/publications/publication884_en.pdf

United Nations International Development Organisation (UNIDO). (2006). Analysis of financing models for small hydropower plants on the basis of case studies. Retrieved from http://www.unido.org/fileadmin/media/documents/pdf/financial_models.pdf

Wohlgemuth, N. (n.d.). Innovative Financing Mechanisms for Renewable Energy Systems in Developing Countries. Sustainable Development International, 37-42. Retrieved from http://infohouse.p2ric.org/ref/40/39699.pdf

\section{Copyrights}

Copyright for this article is retained by the author(s), with first publication rights granted to the journal.

This is an open-access article distributed under the terms and conditions of the Creative Commons Attribution license (http://creativecommons.org/licenses/by/4.0/). 